\title{
Typical Construction Technology and Method of UHV Main Transformer
}

\author{
CHEN Kerui ${ }^{1}$, HAN Yang ${ }^{2}$, WANG Lei ${ }^{3}$, PEI Ying ${ }^{4}$, HE Dengsen $^{5}$, ZHANG Yan ${ }^{6}$, GAO Nannan ${ }^{7}$, LI Hongbo ${ }^{8}$, LI Pei ${ }^{9}$, \\ GUO Liangfeng ${ }^{10}$ \\ ${ }^{1-10}$ State Grid of China Technology College 250002, Jinan, China
}

\begin{abstract}
According to the latest experience of UHV transformer on-site installation work, according to the rules and regulations requirements, the construction process and process of UHV transformer are summarized, and a typical UHV transformer construction method commonly used at present is obtained. Operation comes down to the arrival of acceptance, annex installation, vacuum oiling and hot oil circulation, sealing inspection, standing five processes. In accordance with the above process steps, this paper is divided into five parts to introduce the process and method of UHV transformer construction in order to guide the on-site construction and training teaching.
\end{abstract}

\section{Introduction}

UHV is in the promotion of the use of power grids in China greatly enhanced power transmission capacity and efficiency. The data show that a $1000 \mathrm{kV}$ line is equivalent to $500 \mathrm{kV}$ line transmission capacity $4-5$ times the transmission distance is $500 \mathrm{kV}$ lines $2-3$ times. At the same time, in accordance with the national grid company data, transmission of the same energy situation, through the $1000 \mathrm{kV}$ line transmission land corridor occupies only $500 \mathrm{kV}$ line area of $60 \%$ [1]

The core equipment of UHV transmission substation is $1000 \mathrm{kV}$ main transformer, its installation technology and construction quality directly affect the substation and even the whole UHV project construction quality and level. In order to improve the installation quality of UHV main transformer and ensure the safe running and stable operation of the main transformer, the author has compiled this article according to the relevant requirements and can provide the reference for $1000 \mathrm{kV}$ main transformer installation and construction. [2-4]

\section{Main Transformer Construction Workflow}

UHV main transformer construction work is more complex, with clear steps and strict process. The process includes the arrival of the acceptance, annex installation, vacuum oiling and hot oil circulation, sealing inspection, standing and other steps [3-7], As shown below.

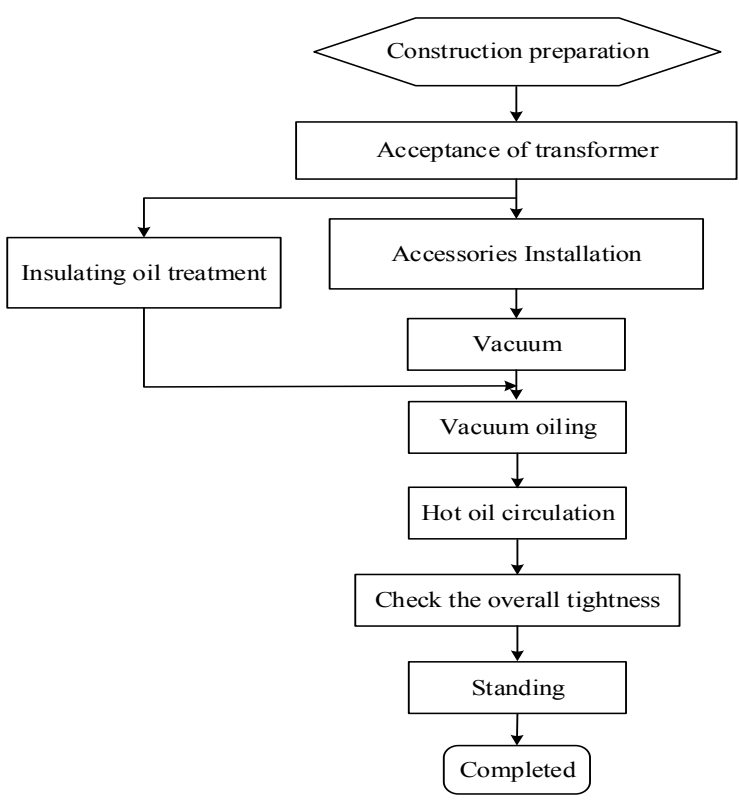

Fig.1. Main transformer construction work flow chart

\section{Arrival acceptance}

\subsection{Acceptance of the transformer body arrival}

According to equipment manufacturers to verify the size of the transformer base, and draw the basis of the design drawings based on the central line for the use of equipment transport unit in place.

After installing the transformer in the collision recorder, check the record of every collision recorder. 
The level acceleration of the transformer during transportation is not more than $3 \mathrm{~g}$ and the vertical acceleration is less than $3 \mathrm{~g}$, and the collision recorder and collision records should be kept properly.

After the body transported to the scene, immediately check whether the moisture after shipping the product. Whether the product is moisture based on the initial:

a) The nitrogen pressure of the nitrogen filling body is greater than $0.01 \mathrm{MPa}$ at normal temperature;

b) Take the oil residue in the main test, pressure, micro-water, dielectric loss should be consistent with the relevant provisions.

\subsection{Accessories out of the box acceptance}

1) In accordance with the demolition table and packing list out of the box inventory components, accessories, the provisions of the contract spares and special tools, the number of physical objects are consistent with the packing list, is damaged.

2) Check all valve operation is flexible, no jamming; opening and closing position is indicated on the valve position corresponds to the valve and the flange connection is sealed good tank should be no deformation damage.

3) Accessories should be complete, no corrosion and mechanical damage and seal well. Cooling device, CT elevated seat, casing and other visual inspection intact. The surface of the oil conservator should be free from collision deformation, corrosion, paint layer intact. Oil-filled casing of the oil level should be normal, no leakage of oil, porcelain body without injury.

4) Spare parts and complete information.

\subsection{Parametric Studies}

With the finite element models validated, further numerical analyses were done to generate results over a wider range of geometries and local slenderness to evaluate whether DSM is suitable for hot-rolled RHS/SHS stub columns. A total of 864 different RHS/SHS were modeled, which cover three kinds of yield strengths (S275, S355, S460) and four kinds of cross-sections defined in EN 1993-1-1 [1]. The value of aspect ratio $(\mathrm{h} / \mathrm{b})$ varies from $1 \mathrm{~mm}$ to $3 \mathrm{~mm}$, the value of $B$ varies from $40 \mathrm{~mm}$ to $80 \mathrm{~mm}$, the value of $\mathrm{H}$ varies from $40 \mathrm{~mm}$ to $200 \mathrm{~mm}$ and the value of inner radius which equals to the value of thickness varies from $1.5 \mathrm{~mm}$ to $5 \mathrm{~mm}$. The material properties used in the parametric studies are presented in table 2 and other properties that are not mentioned in this paper can refer to EN 1993-1-1 [1] and ECCS [7].

\section{Accessories Installation}

\subsection{Installation of oil conservator}

1) The oil conservator should be cleaned and kept dry before installation. The capsule inside the oil conservator should be complete without damage, the capsule mouth is well sealed and the breathing is smooth.

2) Lifting of oil conservator: a. The angle between strap and oil conservator should be greater than 45 degrees.

3) Assemble the tube before the heat with the transformer oil flush tube inside.

4) According to the drawings, manufacturers mark, the tube assembly; tighten the flange connection bolt force moderate, uniform, according to manufacturers torque requirements fastening, and pay attention to whether the rubber band inside the pad is positive.

5) Oil level indicator should be correct, no false oil level. In order to shorten the exposure of the body to the air, the assembly of the external accessory is carried out at the same time as the internal inspection - that is, the total assembling work. The total assembly, the inflatable hose changed to the main transformer oil injection valve to the tank and the continuous filling into the dry air.

\subsection{Cooler installation}

1) The cooler has been installed in accordance with the provisions of the manufacturer before the pressure value seal test qualified

2) The external oil pipeline should be thoroughly cleaned before installation and clean.

3) The cooler bracket, the upper and lower part of the first tube installed to the transformer body. Before installation, remove the corresponding cover plate from the joint cover and cooler tube, and wipe the oil on the port with a clean cloth.

4) Cooler hoisting: the choice of two cranes, the main transformer before and after the installation of a Taiwan. 1. Sling with a hanging hook hanging hook on the top of the cooler ring, the cooler stand up slowly, cooler end (with the end of the oil plug) to cushion rubber to prevent the cooler stand up and the ground bumps and damage. 2. The angle between the strap and the cooler should be greater than 45 degrees.

5) Open the cooler lower part of the oil plug, let cooler internal residual oil tighten the oil drain plug.

6) Open the cooler oil channel cover, install the cooler on the bracket and dock with the body oil channel, fasten the bolt and then remove the harness.

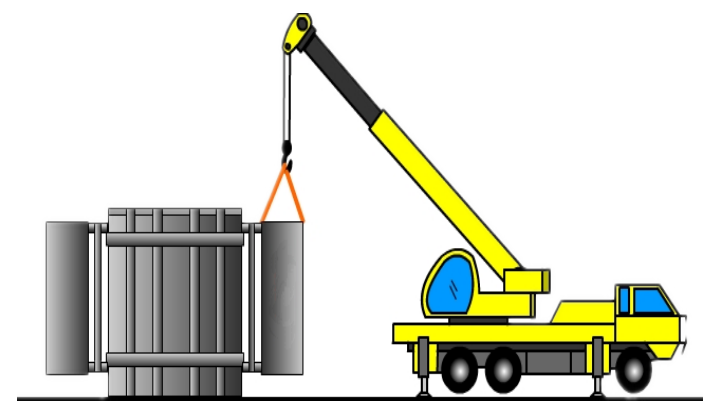

Fig.2. Cooler and the body docking

7) Install the oil pump on the cooler oil line.

8) After the installation of all the fans check whether the normal operation, the oil pump steering is correct, no abnormal noise. 


\subsection{Installation of high - pressure outlet}

1) Lifting the lower support frame of the high-pressure outlet device to the installation base.

2) Remove the connection between the high-voltage lead and the transport cover, and then remove the transport cover on the mounting flange on the fuel tank.

3) High-pressure outlet device filled with dry air transport, it should first release its positive pressure inside the dry gas, and then remove the transport side of the connection with the body cover.

4) Prepare 4 5t manual hoists Press (Fig. 3) to connect the sling and manual hoist. The lifting hook makes the main sling slightly force.

5) Tighten the manual hoist, so that auxiliary sling force.

6) Lifting hook, and adjust the manual hoist, so that the outlet device is adjusted to the installed state.

7) The high-pressure outlet device hoisting to the tank, and connect the lead.

8) Install the support fastener between the outlet device and the bracket, and tighten the outlet device.

9) Remove the upper transport cover from the outlet unit.

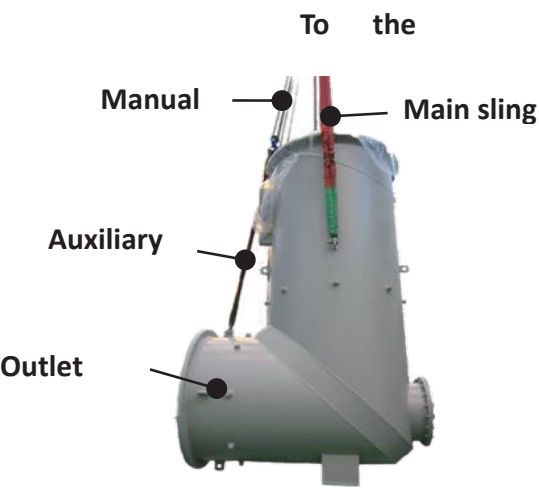

Fig.3. Lifting device lifting reference

\subsection{Raise the seat mount}

1) Before the installation of elevated seat, should complete the current transformer test.

2) Elevated seat lifting: the angle between the sling and the elevated seat should be greater than 45 degrees.

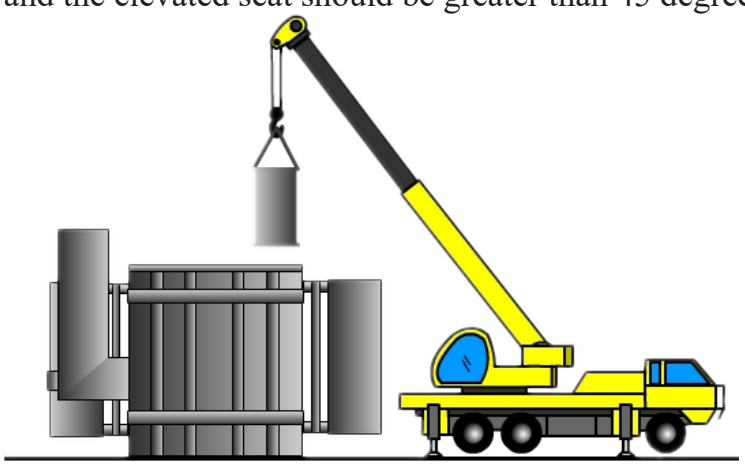

Fig.4. Higher installation

3) When installing the elevated seat, the venting position should be at the highest point of the raised seat.

4) The current transformer and the center of the elevated seat should be consistent, the insulation tube should be installed firmly to ensure that the transformer lead wire will not collide with it.

5) Before installing the elevated seat, store the dry test strip in the elevated transport cylinder and check whether the color of the test paper is changed to determine whether the outlet insulation cylinder is damp during transportation.

\subsection{High - pressure casing hoisting}

$1000 \mathrm{kV}$ high-voltage casing hoisting and installation work, pay attention to the weight of high-pressure casing, length, transformer height, and $1000 \mathrm{kV}$ outlet device.

1) The casing installation direction for the vertical installation, lifting with two cranes.

2) The casing dedicated spreader fixed to the casing, so that both ends of the soft strap, respectively, through the spreader fixed to the casing flange rings, the other end hanging on the main crane hook. Also take a harness, one end hanging in the flange rings, the other end hanging in the auxiliary crane.

3) The beginning of a certain level of lifting height of the casing, the auxiliary crane hook brake, the main crane hook slowly rise, so that the casing slowly erected until the auxiliary crane hook is not force, take off and auxiliary crane connection Sling, remove the casing tail protection tube, continue to rise until the casing test rack.

4) Casing hoisting flow chart.

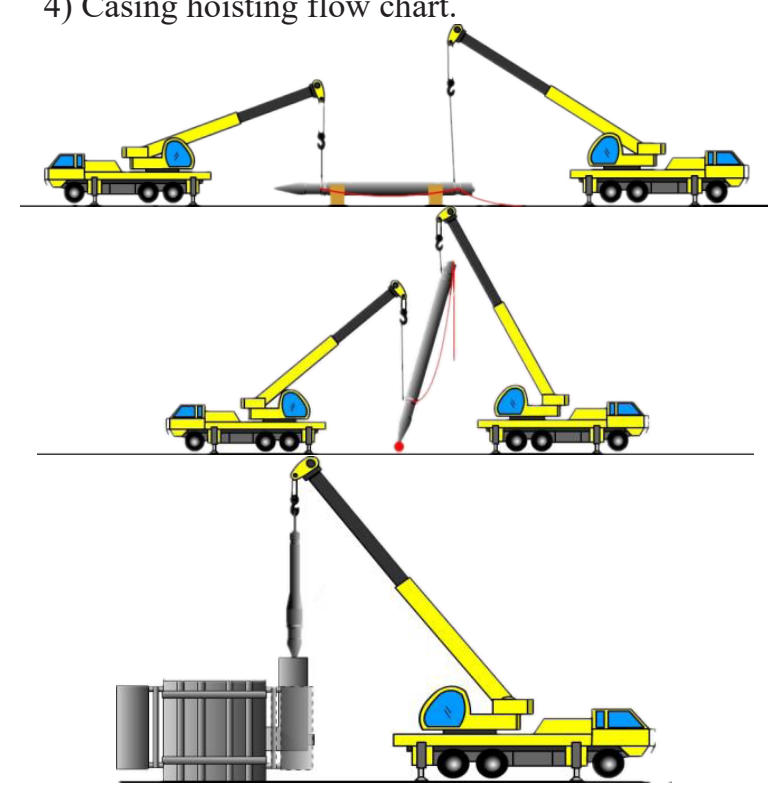

Fig.5. Schematic drawing of high - pressure casing hoisting

\subsection{Internal lead connection}

(1) High-voltage casing of the lead installation, the use of guide-type installation, must be strictly in accordance with casing instructions for. Advance the lower part of the guide rod and lead wire connection, from the elevated seat into the hole with a wrench to tighten the guide rod connection, with a locking fluid locking. Fasten the casing head bolts with a torque wrench as per the casing instructions. The casing lead connections are as follows: 


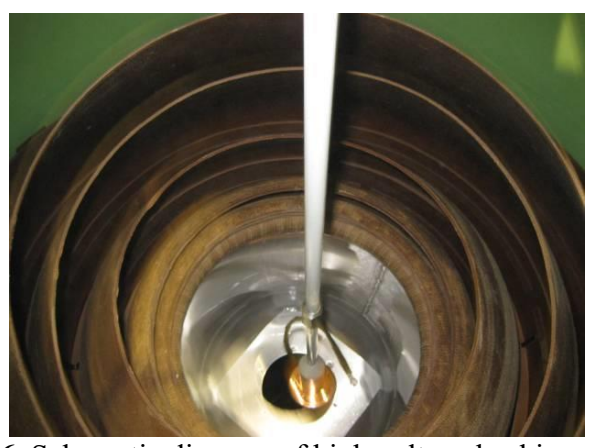

Fig.6. Schematic diagram of high voltage bushing

2) When installing and dropping the casing, observe the cooperation between the casing and the lead wire and the outlet device, avoid damage, and make the lower part of the casing and the lead wire fully enter the insulated ball of the outlet insulation. The specific size complies with the drawing requirements. Casing tail and pressure ball position shown below:

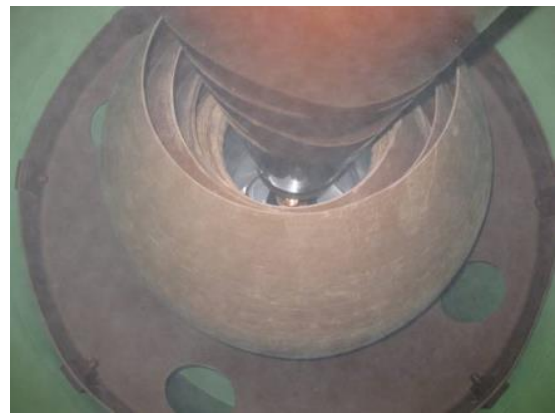

Fig.7. Casing tail and pressure ball position

3) The casing flange and the top of the current transformer flange evenly bolted symmetrical tightening, revealing the deduction for the $2 \sim 3$ buckle and pay attention to the casing oil table outward.

4) The contact surface of the terminal to be wiped, no dirt, oxide film and other impurities impeding the existence of electrical contacts. The connecting piece of the connecting terminal should be straight, no burr, flash. Fastening bolts on both sides with a disc spring washer. The tightening bolts are tightened according to the tightening torque of Table 1. To ensure good electrical contact.

5) After installing the casing head are installed pressure ring.

\subsection{Other accessories installation}

\subsubsection{Seal ring installation}

1) General requirements Manufacturers will be transported to the scene when the installation has been installed in the ring with a new ring replacement of all.

2) All flange connections are sealed with oil-resistant seals. The seals must be free from distortion, distortion, cracks and burrs, and the gasket should be dimensioned to match the flange face. clean

3) Keep the sealing ring and the sealing ring surface

\subsubsection{Tank sealing}

1) Clean the inside of the fuel tank.

2) According to the record check, inventory has been removed all the tools and materials.

3) Close the dry air generator outlet valve.

4) with the cover closed into the hole and other flange

\subsubsection{Installation of gas relays}

1) Gas relays should be inspected before installation.

2) Gas relay should be installed horizontally, the arrow on the top of the logo should point to the conservator, the connection with the tube should be sealed well.

3) Gas relay should have moisture and anti-water function.

4) Cable leads in access to the gas relay should be dripping bend, into the line hole should be sealed tightly

\subsubsection{Installation of pressure relief valve}

Pressure relief valve should be installed in the correct direction, the valve cover and the internal rise should be clean, sealed well, electrical contacts should be accurate, insulation should be good.

\subsubsection{Temperature measurement device installation}

1) Thermometer installed before the check, the signal contact action is correct, conduction is good; winding thermometer should be set according to the provisions of the manufacturer.

2) The top of the thermometer seat should be noted with transformer oil, the seal should be good, no oil leakage phenomenon.

3) Expansion of thermometer fine metal hose shall not be crushed or sharp twist, bending radius of not less than $50 \mathrm{~mm}$.

\section{Vacuum oiling and hot oil circulation}

\subsection{The transformer is evacuated}

1) the transformer tank sealed with a qualified transformer oil to clean the bottom of the tank, no debris left over. Then seal all open covers. Check the vacuum pump, vacuum line transformer around the valve status and sealing conditions, open the tank and the radiator between the valves.

2) Connect the vacuum pump tubing to the special butterfly valve located at the top of the tank. Connect the vacuum gauge.

3) Before evacuating, the valve between the accessories (eg oil pillow) and the tank which can not bear the vacuum must be closed. For parts that allow vacuuming, the radiator should be evacuated at the same time.

4) Start the vacuum pump and slowly open the vacuum suction valve. Pumped to about 2 hours after the suspension (first close the exhaust valve, then stop the vacuum pump), check the seal of the tank connection. If 
suction sound, should be promptly handled. When the elimination can not afford to break vacuum treatment, the air must be filtered through the dry silica gel before being placed in the transformer. In the vacuum process, the vacuum rose slowly or a large pressure leak, that may leak, should be promptly dealt with.

5) Vacuum, it should be observed at any time record the deformation of the tank, the maximum deformation of not more than 2 times the wall thickness, while attention to the deformation of the radiator, if the problem promptly contact with the manufacturer representatives.

6) Vacuum to $13 \mathrm{~Pa}$, the transformer leakage rate test. The results of the test results do not meet the requirements, check all the joints and tighten, do leakage rate until qualified.

7) After completion of the leak test, continue to vacuum to $13 \mathrm{~Pa}$ or less, to maintain $\geq 48$ hours (pressure to 24 hours).

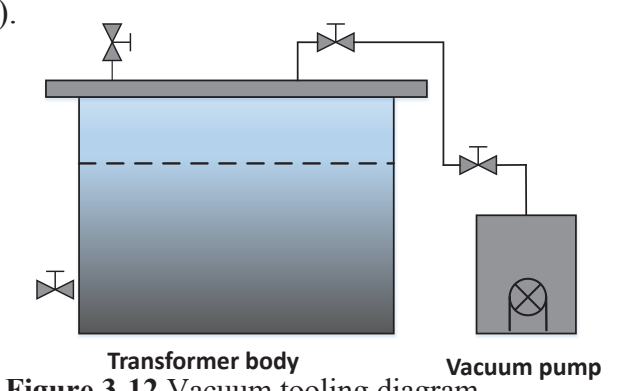

Figure 3-12 Vacuum tooling diagram

\subsection{Vacuum oiling}

1) Start the vacuum oil filter The transformer oil is injected into the injection valve, continuous vacuum during oil filling, and adjust the filling speed to maintain the vacuum within $\leqslant 20 \mathrm{~Pa}$ (modulation is not greater than $133 \mathrm{~Pa}$ ), but the maximum flow rate shall not exceed $5 \mathrm{t} / \mathrm{h}$, oil temperature $60 \pm 5 \mathrm{C}$, until the oil surface under the vault to $200 \mathrm{~mm}$.

2) Continue to vacuum $2 \mathrm{~h}$, close the butterfly valve and the unit, the vacuum gauge and vacuum line switch to the conservator breathing tube Department, open the conservator breathing mouth valve, exhaust port and breathing port Unicom valve, close the exhaust valve, Install the gas relay, open the $80 \mathrm{~B}$ butterfly valve at both ends, and draw the vacuum from the breather port of the conservator. Continue to fill the oil tank to half the oil level, stop the vacuum, stop oiling, close the exhaust port and breathing port Unicom valve, close the vent valve.

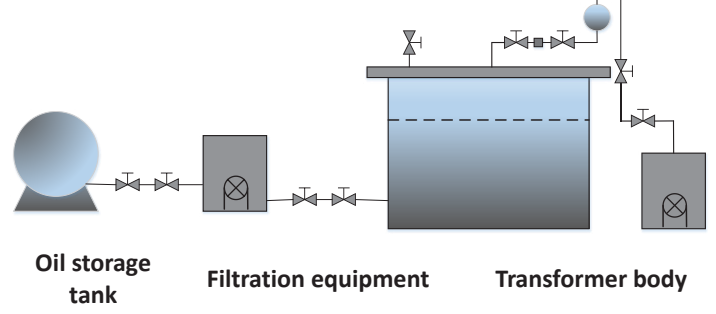

Fig.8. Vacuum oiling equipment diagram
1) In order to eliminate the installation process of insulation of the surface of the body moisture, the use of the way up and down the hot oil circulation.

2) Hot oil circulation before the tubing should be vacuum, the tubing in the air pumping clean.

4) Cycle time should not be less than $96 \mathrm{~h}$, cycle flow $8 \sim 10 \mathrm{~m} 3 / \mathrm{h}$.

5) During the hot oil circulation, the outlet temperature of the oil filter should be controlled within $60 \pm 5{ }^{\circ} \mathrm{C}$, and the outlet temperature of the transformer should be controlled within $60 \pm 5^{\circ} \mathrm{C}$.

6) The hot oil circulation should meet the following conditions before the end:

Hot oil cycle time of not less than $96 \mathrm{~h}$, the cycle time of not less than $3 \times$ total transformer oil / oil through the oil hourly.

7) The transformer outlet temperature is reached every 2 hours after opening a group of cooler valve for hot oil circulation, to prevent the cooler affect the hot oil circulation effect.

8) After the end of the hot oil circulation, should close the oiling valve, open the transformer all components, accessories and piping bleed valve exhaust.

9) The use of machinery and equipment and insulating oil processing part of the same.

5 The whole sealing test and standing

The overall sealing test: the transformer as a whole (including the cooling system) and the oil conservator can withstand the highest oil level of $30 \mathrm{kpa}$ static pressure on the oil seal test, the test time for $24 \mathrm{~h}$, no leakage and damage.

After the hot oil circulation, must be in the transformer before the high-voltage test must be placed more than $168 \mathrm{~h}$ (adjustable voltage compensation more than $72 \mathrm{~h}$ ) during the static, the product static interval of 24 hours, the use of all components of the transformer, accessories and piping All deflate venting pieces, oil spill immediately tighten the venting plug, wipe the spilled oil Gloves of the gasket is small, so to moderate force, it is necessary to seal good and do not twist bad pads.

\section{Conclusion}

In this paper, the construction of UHV main transformer in China is fully considered, and the construction process and process of the UHV main transformer are summarized and the construction process of a typical UHV transformer is put forward with reference to relevant rules and regulations. The construction process is attributed to the acceptance of the arrival of the annex to install the vacuum oil and hot oil circulation, sealing inspection, standing five parts, the steps of convergence reasonable and tight, in line with the general UHV transformer installation process customary, High-voltage main transformer on-site construction operations, and provide reference for related fields of training and teaching.

\subsection{Hot oil circulation}




\section{References}

1. Liu Zhenya "Innovation of UHV AC transmission technology in China" Power System Technology vol. 37 No. 3 pp. T1 - T8 2013.

2. Dept. of Science \& Technology: New Technology Catalog of SGCC (2014) Beijing: China electric power press 2014.

3. Liu Zhenya Equipment Research of UHV AC Pilot Demonstration Project in China Beijing: China Electric Power Press 2010.

4. H. Weng X. Lin "Studies on the unusual maloperation of transformer differential protection during the nonlinear load switch-in" IEEE Trans. Power Del.</em> vol. 24 no. 4 pp. 1824-1831 Oct. 2009.

5. R. Hunt J. Schadfer B. Benter "Practical experience in setting transformer differential inrush restraint", Proc. 61st Annu. Georgia Tech Protect. Relay. Conf. $<$ em> pp. 118-141 2007-May.

6. D.Shao X. Yin Z. Zhang W. Chen D. Chen "Experiment research on differential protection for UHV transformer in China", Proc. IEEE Power Energy Soc. Gen. Meeting, pp. 1-5 2008-Jul.-20-24.

7. H. Weng X. Lin P. Liu "Studies on the operation behavior of differential protection during a loaded transformer energization", IEEE Trans. Power Del. vol. 22 no. 3 pp. 1386-1391 Jul. 2007. 